Revista de Psicología Vol. 31 (2), 2013 (ISSN 0254-9247)

\title{
Las psicologías del área social-organizacional en el Perú: 2003-2012
}

\author{
Federico R. León ${ }^{2}$ \\ Socio, León \& Bustamante Consultores
}

\begin{abstract}
Este artículo evalúa cuatro subdisciplinas de la psicología peruana. Un desafío para el psicólogo organizacional es ajustar sus buenas prácticas a la evidencia científica; aquellas formuladas en Estados Unidos o Europa no son necesariamente relevantes a toda empresa y población local. La psicología del consumidor tiene impacto popular, pero los cultores no divulgan sus métodos y hallazgos con rigurosidad. Las contribuciones de la psicología comunitaria podrían fortalecerse si las hipótesis de origen psicoanalítico u otras perspectivas, fuesen formuladas con nitidez y sometidas a metodologías convencionales de evaluación de intervenciones. La psicología social peruana está contribuyendo al conocimiento de la realidad nacional y presenta hallazgos originales en temas de reducción de pobreza, identidad nacional, bienestar personal y efectos de la geografía.

Palabras clave: psicología social, psicología organizacional, Perú
\end{abstract}

\section{Psychologies of the Social-Organizational Area in Peru: 2003-2012}

This article assesses four subdisciplines of Peruvian psychology. Organizational psychologists face the challenge of adjusting their good practices to scientific evidences; those studied in the United States or Europe are not necessarily relevant to all types of Peruvian organizations and populations. Consumer psychology has achieved popular impacts, but practitioners, either qualitative or quantitative, do not disseminate their methods and findings with rigor. Community psychologists' contributions could improve if their hypotheses originated in psychoanalysis or other perspectives were formulated with clarity and tested by means of conventional techniques designed for the evaluation of interventions. Peruvian social psychology is contributing to the understanding of national realities and has generated original findings concerning poverty reduction, national identity, personal wellbeing, and effects of geography.

Keywords: social psychology, organizational psychology, Peru

1 Nota del Autor: El autor agradece las entrevistas concedidas por Rolando Arellano, Nina Bustamante, Eduardo Castillo, Eduardo Cobián, Carmen Masías, Mario Tueros, Tesania Velásquez y Jorge Yamamoto, así como la ayuda de Vanessa Landavery en la búsqueda bibliográfica.

2 Doctor en Psicología y profesor en la Universidad San Ignacio de Loyola. Socio, León \& Bustamante Consultores. Contacto: Av. Javier Prado 7427, Lima 3; federicorleone@gmail.com 

Es difícil que una disciplina alcance un nivel de desarrollo óptimo sin detenerse a evaluar periódicamente sus logros y vacíos. Atendiendo a esta necesidad, el Colegio de Psicólogos del Perú/Lima me encargó preparar una panorámica de la psicología social y organizacional en el Perú y presentarla al Primer Congreso Internacional de Comportamiento Social para el Desarrollo Humano (Lima, mayo 2011). Este artículo ofrece una evaluación actualizada de las psicologías del área social-organizacional abarcando la década del 2003 al 2012. Livia (2008) hizo una descripción poco exhaustiva de la producción científica del área como parte de su evaluación de las investigaciones y posgrados de la psicología peruana.

En la Figura 1 está mi visión global del campo. La clasificación de las cuatro subdisciplinas, además de estar definida por la relación de la psicología con otras disciplinas, lo está por los ejes vertical y horizontal. El primero concierne a la naturaleza del cliente. La psicología organizacional y la del consumidor sirven intereses particulares (corporaciones, instituciones públicas, organizaciones no gubernamentales) mientras que la social y la comunitaria están al servicio de intereses más heterogéneos (una comunidad, la sociedad en general). La dimensión horizontal distingue posturas abiertas y cerradas.

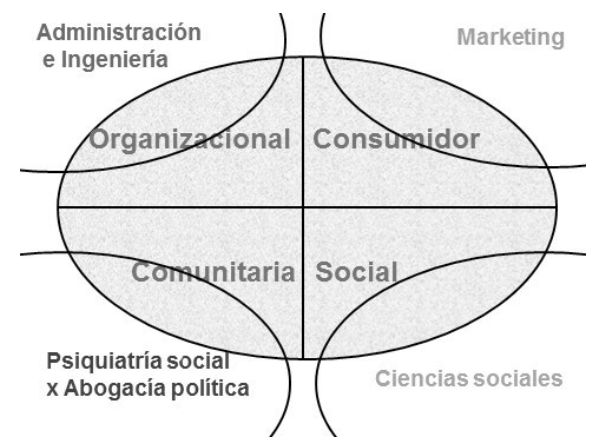

Figura 1. Las psicologías del área social-organizacional 
El psicólogo social y el del consumidor necesitan abrir la mente para hacer su trabajo, que consiste en obtener información y desarrollar conceptos. En cambio, el psicólogo organizacional y el comunitario deben seleccionar buenas prácticas y aplicarlas con cierta dosis de dogmatismo para conseguir resultados. Demográficamente, las cuatro especialidades no tienen la misma importancia; sobre esto habrá que lograr mayor precisión mediante encuestas y otros medios de recolección de información, aunque es evidente que la organizacional tiene a las mayorías. También es evidente que la de la Figura 1 es una división abstracta, pues las personas propiamente dichas migran de un área a otra y, a veces, es difícil definir su identidad. Hay migraciones dentro de la psicología, como es mi caso (de organizacional a social, pasando por psicología de la salud), y no es raro que la carrera más exitosa del psicólogo del área culmine en su conversión a gerente de recursos humanos, dueño de una empresa de marketing o experto en desarrollo. Mi estrategia para el diagnóstico de cada área sacrificó el criterio de representatividad.

El propósito fue poner el foco en los niveles de excelencia de cada subdisciplina, bajo el supuesto que las falencias que se encontrara en las élites generarían lecciones para todos los niveles. Para este fin, entrevisté a dos psicólogos muy destacados por área y a representantes de las universidades que respondieron a mi pedido de una reunión. De mis conversaciones con ellos, una búsqueda intensiva por Internet y mi propia experiencia y reflexiones derivé implicancias para la formación académica, actividad profesional y desarrollo científico. Mi sesgo personal está reflejado en la atención prestada a las obras empíricas de la literatura (es decir, estudios sobre temas bien delimitados que involucran observaciones, mediciones, o afrontes cualitativos), aun las de pobre calidad. Demasiada tinta se gasta en escribir ensayos genéricos y repetitivos; solo cuando un artículo no-empírico sobresalía por su originalidad fue tomado en cuenta. 


\section{Psicología organizacional}

La psicología organizacional tiene su núcleo histórico y acontecer presente en el traslape de la psicología con la administración y, secundariamente, la ingeniería. En el Perú, ha sido recientemente evaluada mediante una encuesta a psicólogos organizacionales por Flórez y Salas (2011), quienes distinguieron cinco tipos de actividad. Yo he agregado una sexta actividad, referida a la reingeniería de tareas.

\section{Selección de personal}

En selección de personal para cubrir vacantes trabaja gran parte de los psicólogos organizacionales. Lo hacen dentro de corporaciones industriales, comerciales y otras, generalmente grandes, con frecuencia subsidiarias de transnacionales, así como en empresas consultoras locales o transnacionales. También lo hacen en el aparato estatal y en organizaciones no gubernamentales (ONG). Su función es ampliamente reconocida por las organizaciones. Las actividades de selección y evaluación de personal abarcan todo tipo de ocupaciones y niveles organizacionales, desde obreros no especializados hasta gerentes generales y actualmente se ve una gran diversidad de enfoques y técnicas. Hay una minoría de psicólogos puramente clínicos que ofrecen a las empresas diagnósticos de habilidades y personalidad de los candidatos, pero la mayoría son psicólogos que en el pregrado concentraron su carga académica en cursos relativos a la psicología organizacional y aplican un enfoque psicométrico en las organizaciones. Me refiero con esto al uso de puntajes derivados de tests de habilidades y de personalidad para predecir el desempeño laboral de la persona evaluada. Por ejemplo, se utilizó bastante en el siglo pasado el 16PF, el test de personalidad de Cattell, estandarizado en Venezuela y Colombia. Ahora se utiliza tests norteamericanos, colombianos y de otros países rigurosamente construidos que pueden alquilarse por Internet. También se encuentra un enfoque mixto, es decir, el uso combinado de tests psicométricos y proyectivos. 
Amplias mayorías de psicólogos organizacionales del Perú enfrentan el desafío de entregarse a actividades altamente especializadas apenas terminan el pregrado, que no les da información suficiente sobre administración y organizaciones. Como dicen Flórez y Salas (2011), una de las razones por las cuales el psicólogo organizacional no recibe el reconocimiento que quisiera está en su poca comprensión del ambiente de negocios, Esta situación está cambiando. Hay psicólogos organizacionales que han conseguido un mejor entendimiento de las organizaciones gracias al complemento de una maestría en administración general, que le permite hablar de igual a igual con sus clientes corporativos y entrevistar a los candidatos a un puesto comunicándose en su propio lenguaje. Otros caminos son los de hacer una maestría en psicología organizacional o en recursos humanos. Los psicólogos organizacionales pueden alcanzar un alto nivel de especialización en evaluación y selección de personal. En los últimos 20 años, candidatos venezolanos, ecuatorianos, chilenos, dominicanos y de otros países eran traídos por una gran empresa de cosméticos a Lima para ser evaluados en sesiones cara a cara con un enfoque mixto de evaluación que incluía al test de Rorschach. Recientemente se logró reducir el costo gracias a las alternativas que representan las entrevistas por Skype y los tests por Internet, pero aun así el enfoque mixto sigue siendo caro y elitista. Por ejemplo, el test de necesidades de McClelland sigue siendo proyectivo on-line y no es fácil de interpretar. $Y$ si de lo que se trata es de seleccionar 200 obreros para la obra que comienza dentro de una semana, el enfoque mixto es evidentemente inaplicable.

Estar bien formado como psicólogo organizacional no solo supone haber aprovechado las enseñanzas académicas y haber acumulado experiencias, sino también estar al tanto de los progresos contemporáneos en buenas prácticas. Considérese el caso de la estabilidad emocional, un factor de personalidad que está entre los Big Five y se refiere a la medida en que una persona es calmada, equilibrada bajo presión y generalmente libre de, o con control sobre, emociones negativas como ansiedad, depresión o cólera. Está demostrado que el control emocional ayuda a la gente a superar las emociones distractoras que desvían la 
atención de la tarea que uno está ejecutando; también ayuda a evitar interferencias en las relaciones interpersonales y el trabajo en equipo. De allí que se espere que mientras mayor sea la estabilidad emocional de una persona, mejor será su desempeño laboral. Muchos psicólogos organizacionales peruanos usan el test de Machover, "el hombre bajo la lluvia", y otros tests de personalidad con poblaciones obreras y predicen mejor desempeño laboral mientras más estables emocionalmente diagnostican a sus candidatos. Sin embargo, esto acaba de dejar de ser una buena práctica en Estados Unidos, pues en un estudio publicado en el Journal of Applied Psychology aparece evidencia de que las cosas no son tan simples (Le \& cols., 2011). La relación entre estabilidad emocional y desempeño laboral es casi lineal, aunque con rendimientos decrecientes, cuando la tarea es compleja, pero curvilineal cuando la tarea es simple. A partir de un puntaje medio de estabilidad emocional, mientras más estable sea la persona, peor será su desempeño si la tarea es simple. La moraleja es que las buenas prácticas no son estáticas y el psicólogo organizacional debe estar atento a su evolución.

Hay en el Perú pocas investigaciones capaces de fortalecer las buenas prácticas de selección y evaluación de personal. Según la encuesta de Flórez y Salas (2011), la investigación es virtualmente inexistente y esto se debe a que los profesores en las universidades tienen una fuerte carga de trabajo enseñando. Yo creo, más bien, que se trata de vacíos de tradición investigatoria y de conexiones entre empresas y universidades, así como de una falta de capacidad de la mayoría de profesores para investigar y de recursos materiales para hacerlo. En la presente revisión de la literatura he visto demasiados trabajos descriptivos de profesores sin vuelo conceptual ni sofisticación metodológica. No obstante ello, la investigación relevante es mayor que cero y valiosa. Solf (2006) evaluó la relación entre un rasgo de personalidad, el tesón y la motivación intrínseca de 228 trabajadores que ocupaban 62 cargos diferentes en una empresa textil, y confirmó su hipótesis de una relación significativa y positiva. Este es un hallazgo importante para la selección de personal, especialmente teniendo en cuenta el rol que las teorías contemporáneas de motivación le dan a la motivación intrínseca (Herrera, 2009). 
Torres y Lajo $(2009,2011)$ hallaron que la dominancia cerebral y la ética profesional se encuentran relacionadas significativamente al desempeño laboral de los docentes de primaria y secundaria, aunque las relaciones se referían a autorreportes y no evaluaciones externas del desempeño. En otro tema, Vicuña, Hernández, Paredes y Ríos (2008) construyeron y le dieron validez de consistencia interna a un test de habilidades para la gestión en la resolución de conflictos; ese estudio destaca por su originalidad y rigor. Dichas habilidades han sido relacionadas posteriormente a los estilos de vida (Paredes 2011). Con un enfoque sofisticado de análisis de ítems, Argumedo, Díaz, Calderón, Díaz-Morales y Ferrari (2005) evaluaron tres escalas de procastinación crónica, y Escurra y Delgado (2008) desarrollaron un test de disposición al pensamiento crítico. Sería bueno que alguien complementara este tipo de esfuerzos agregándoles validez concurrente o predictiva. Palacios, García y Flores (2010) presentaron perfiles emocionales de madres cuidadoras del Programa Nacional Wawa Wasi. Finalmente, hay un estudio muy valioso de Torres y Lajo (2008) sobre la relación entre tres estilos de afrontamiento al estrés, dos de personalidad, tres de burnout, y el desempeño docente en cinco facultades de medicina que debiera replicarse en otras ocupaciones. Su utilización de ecuaciones estructurales permite apreciar los efectos directos e indirectos de los rasgos en el desempeño.

Dadas las pocas investigaciones que se producen en las universidades, los psicólogos organizacionales se ven en la necesidad de ser creativos. Por ejemplo, cuando quieren medir las habilidades de pensamiento crítico, no la disposición al pensamiento crítico, se encuentran con que los tests disponibles fuera del Perú pueden requerir del sujeto conocimientos especializados de economía, que no todos los candidatos potencialmente valiosos necesariamente tienen. Entonces, el psicólogo peruano tiene que crear su propio test y acumular casos para formar un baremo que le permita hacer comparaciones y establecer relaciones con otras variables. Necesitará muchos años para completar una buena base de datos del personal evaluado para una organización cliente o muchas organizaciones clientes que le proporcionen los datos en un plazo más corto. 
El mismo es el caso de tests de inteligencia emocional o escenarios decisionales. Esto no deberían hacerlo los consultores, sino las universidades y las corporaciones capaces de pensar a largo plazo.

\section{Funciones de recursos humanos}

En los últimos 20 años, los psicólogos han reemplazado a los abogados en los puestos de recursos humanos de muchas empresas y se ocupan ahora de diversas funciones. En el campo de la evaluación del desempeño, las empresas encargan el trabajo a sus propios psicólogos pero las hay también que contratan consultores externos encargados de implementar sistemas pre-establecidos. León y cols. (2007a) utilizaron en Jaén y Moyobamba una técnica que probablemente sea la única innovación oriunda del Perú en esta área: el Test de Servicios para evaluar el desempeño de proveedores de planificación familiar, basado en clientes simuladas entrenadas para actuar un guión en la consulta con un proveedor que las cree clientes reales y después de ella anotar sus observaciones en una lista de chequeo (León, Monge, Zumarán, García \& Ríos 2001). La utilidad del Test de Servicios se demostró en la evaluación del sesgo de cortesía. En la literatura internacional había una contradicción entre los resultados de encuestas realizadas a la mujer a la salida de la consulta de salud y focus groups tenidos con mujeres de la comunidad lejos de los centros y puestos de salud. Como en las encuestas se recogía opiniones mayoritariamente positivas respecto al trato recibido en la consulta y en los focus groups llamaban la atención las críticas, se acunó el término sesgo de cortesía, implicando que las opiniones positivas dadas por las mujeres en las encuestas de salida de la consulta eran lenientes. Las bondades del Test de Servicios se expresaron en su capacidad para determinar el porcentaje de consultas en las que la mujer es maltratada en el Perú, India y Rwanda, y permitieron entender que había una magnificación de los materiales negativos aportados por una minoría pequeña de mujeres en los focus groups (León, Lundgren, Huapaya, Sinaí \& Jennings 2007b). Respecto a la evaluación del desempeño docente, Torres, Lajo, Campos y Riveros (2007) 
reportaron correlaciones no significativas entre el rendimiento académico de alumnos universitarios y el desempeño de los profesores. Ello puede atribuirse a que ambas variables se originaron en reportes del alumno. Empleando el método experimental, León (1978) demostró que las notas otorgadas por el profesor afectan directamente la evaluación de su desempeño docente por el alumno.

Otra área es la de capacitación. La expansión de esta área presenta problemas similares a los de la selección de personal. Así como se aplican tests importados, no validados, se utiliza sistemas de capacitación de validez incierta. Por ejemplo, los esfuerzos de fortalecimiento del liderazgo generalmente no toman en cuenta que esta variable no es constante a través de las culturas. Hay un estudio que duró 11 años, de House, Hanges, Javidan, Dorfman y Gupta (2004), quienes compararon 62 sociedades en términos de sus valores y el tipo de liderazgo gerencial preferido. Primero identificaron diez clusters de sociedades, de los cuales uno estaba formado por países latinoamericanos. Luego, a partir del trabajo de Hofstede y sus propios hallazgos, definieron seis tipos de liderazgo: el carismático, el orientado al equipo, el participativo, el de orientación humana, el autónomo y el autoprotectivo. Finalmente, determinaron la medida en que variaba la preferencia por los estilos de liderazgo a través de los clusters culturales. Ciertos rasgos específicos del líder, como ser honesto y motivador, emergían como componentes del liderazgo en todas las sociedades, mientras que otros rasgos, como o ser irritable y asocial, emergían como negativos también universalmente. No obstante, había rasgos de liderazgo que eran contingentes en la cultura. Es decir, un rasgo que podía ser positivo en el cluster anglo o en el germánico podía ser negativo en el cluster latinoamericano. El problema aquí es que los talleres de liderazgo en el Perú promueven conceptos generalmente originados en Estados Unidos, parte de los cuales son de aplicación universal, pero otra parte no. Además, no todos los psicólogos toman en cuenta en la práctica que el Perú todavía es un archipiélago de grupos étnicos y sociales muy distintos. Esta situación va en camino de desaparecer, pero la homogeneización no se va a completar de la noche a la mañana; puede durar décadas. 
Los psicólogos organizacionales tienden a ignorar que la población provinciana, sobre todo la de origen andino, tiene una disposición más colectivista que individualista. Al menos esto es lo que demostró mi estudio en 48 colegios del Perú publicado hace tres lustros (León, 1996) y es lo que siguen encontrando los psicólogos sociales (Espinosa, 2010; Yamamoto \& Feijoo, 2007). Entonces, es probable que esta población responda mejor a los estilos de liderazgo japoneses que a los que tienen éxito en países individualistas como Estados Unidos.

La situación se torna más compleja cuando uno considera el nivel tan diverso de desarrollo de las organizaciones. Hay empresas peruanas que cotizan en la Bolsa de Nueva York. Para ser aceptadas allí han tenido que mostrar sus certificaciones ISO no solo en prácticas financieras y afines, sino también en sus prácticas de recursos humanos, responsabilidad social de la empresa, etc. Esas organizaciones, y las transnacionales asentadas acá, reclutan a la gente más afín a sus valores modernos, globalizados. En ellas es donde probablemente sean más aplicables las buenas prácticas norteamericanas de psicología organizacional. Pero la vasta mayoría de empresas peruanas son medianas y pequeñas y de propiedad familiar y, muchas de ellas, inmersas en la cultura chicha. Alguna universidad debería especializarse en investigar si las buenas prácticas del psicólogo organizacional que trabaja para una empresa, tipo Procter $\&$ Gamble, producen los mismos resultados en una empresa chicha y familiar, y qué demandan las últimas del psicólogo. Otra debiera especializarse en el sector público. Solano (2011) ha revisado la motivación del servidor público y las necesidades de investigación en esta área en el Perú. Lamentablemente, con excepción de las entidades del aparato estatal que conservan el nivel de excelencia con el que fueron fundadas, como, por ejemplo, la Superintendencia Nacional de Administración Tributaria (SUNAT) o el Banco Central de Reserva, probablemente sea muy poco lo que el psicólogo pueda hacer en el sector estatal, donde el criterio de excelencia está ausente y el comportamiento público de sus máximas autoridades (v.g., ministros negociando contratos oscuros en suites de hoteles de cinco estrellas) dańan la moral. En el Perú el servicio público es un calvario sufrido por quienes no pueden colocarse fuera de él, 
sea porque se lo impiden su vocación de servicio, sus creencias antiempresariales o su falta de calificaciones. Establecer la carrera del servicio público y hacerla más atractiva demanda de los gobiernos un sacrificio de sus intereses de clientelaje.

La línea más nutrida de estudios en esta área se refiere al burnout. A algunos de estos trabajos los considero dentro del área organizacional porque se refieren al burnout de grupos ocupacionales específicos, como maestros primarios o secundarios (Delgado, 2003; Yslado, Atoche, Quispe, Ruiz \& Medina, 2011; Yslado, Nuñez \& Norabuena, 2010), profesores universitarios (Ponce, Bulnes, Aliaga, Atalaya \& Huertas, 2005) y profesionales de la salud (Bulnes, 2003; Loli, Arias, Alarcón \& Loli, 2008; Yslado, Atoche, Quispe, Ruiz \& Medina, 2011). Otros pertenecen a esta área porque relacionan el estrés o el burnout con la eficiencia laboral (Hernandez, Rivera \& Paredes, 2004; Torres \& Lajo, 2008) o la baja realización profesional (Arias \& Jiménez, 2012). También han sido estudiados el compromiso organizacional (Arias, Varela, Loli \& Quintana, 2003; Loli \& Cuba, 2007), las competencias del contador público (Tarazona, Maisch \& Arias, 2003) y, especialmente, del psicólogo (Orellana \& cols., 2007; Arenas \& Montero, 2009), así como el ajuste y satisfacción en parejas que trabajan (Prado \& del Águila, 2010). Sobresale la tesis doctoral de Alarco (2010) para la Universidad de Leuven. Analizando respuestas de 651 empleados de ocho organizaciones limeñas, ella contrastó los conceptos de empleabilidad e inseguridad en el trabajo. Los encontró negativamente correlacionados, pero no parte de un continuo sino con antecedentes y consecuencias distintos, y descubrió que la empleabilidad se relaciona con la satisfacción con el trabajo pero también con cinismo. Esta investigación es de una sofisticación conceptual y empírica poco común a nivel local.

\section{Cultura y clima organizacional}

Hay psicólogos organizacionales que intentan determinar cómo el ambiente o las condiciones de trabajo son influidas por la cultura o el clima organizacional. Parece que las tesis de pregrado sobre estos 
tópicos son populares (Flórez \& Salas, 2011). Casi todos los estudios toman un cuestionario pre-existente y lo adaptan. También se usa la técnica de focus groups para identificar variables de clima organizacional y los psicólogos informan sobre sus hallazgos a la gerencia para que esta tome acciones. Lo que domina el panorama en el Perú es un sistema creado aparentemente fuera de la psicología, llamado Great Place to Work. Se desconoce la confiabilidad y validez del instrumento usado en esas mediciones del clima, pero las principales organizaciones compran el servicio, especialmente para fortalecer su imagen, pues el sistema proporciona un benchmarking de corporaciones peruanas y extranjeras. El sistema seguramente mide satisfacción laboral más que clima, pero tal vez tenga algunos resultados positivos, pues los gerentes que quieren hacer sobresalir a su corporación le dan generalmente recursos extra a su departamento de recursos humanos con tal de aumentar uno o dos peldaños en el siguiente informe de Great Place to Work. Algún programa universitario de psicología organizacional podría asumir el desafío de competir en este campo desde una trinchera científica. Tendría que comenzar por definir con rigor lo que entiende por clima organizacional. Mi profesor de Maryland Ben Schneider definió el clima organizacional como "una descripción ambiental, molar e interna, de las prácticas y procedimientos de una organización que es compartida por los miembros" (Schneider, 1975). Nótese que esta definición, la más aceptada hasta la actualidad (Schneider, Ehrhart \& Macey, 2012), pone énfasis en las percepciones compartidas del personal respecto al ambiente organizacional y permite diferenciar el concepto de clima del de cultura organizacional, que es un asunto de juicios y valores y ha sido tratado en la literatura organizacional de manera más vaga y antropológica. El estudio de House y cols. (2004) en 62 sociedades demostró que los ítems sobre clima (referidos a cómo son las cosas) y cultura (referidos a cómo deberían ser las cosas) producían patrones divergentes de respuesta. Se mide además climas específicos, como el clima de seguridad industrial, el de innovación, el de silencio o el de miedo. El segundo paso indispensable para llevar el tema a un nivel científico sería establecer las relaciones entre clima y otras variables organizacionales y personales. 
La investigación científica sobre clima y cultura organizacional es muy escasa en el Perú, pero interesante. Bulnes y cols. (2004) no encontraron una relación significativa del clima organizacional con el burnout entre 93 profesionales de la salud de diversas entidades públicas. Thorne, Centeno y Wentzell (2009) trataron a los centros educativos como organizaciones cuando hicieron una aplicación al aula del concepto de clima para comparar colegios laicos y religiosos del Callao, y estatales y particulares de Lima; su foco estuvo en el ambiente de trabajo, ritmo de clase, interés por el alumno, clima de competición, y cooperación y trabajo en grupo. Matos y Lens (2009), en cambio, se ocuparon de la cultura escolar, entendiéndola como los valores de logro transmitidas por los profesores. Ellos aplicaron ecuaciones estructurales para establecer relaciones entre la cultura escolar, las metas del alumno y su rendimiento en colegios públicos y privados de Lima. A este tipo de modelamiento es a lo que tiende la psicología científica contemporánea no-experimental.

\section{Desarrollo organizacional}

En el área de desarrollo organizacional, el principal concepto se refiere a transformaciones de los sistemas sociales dentro de la organización y al cambio de mentalidades como base para el cambio de conductas. Por ejemplo, el esquema de Yukl (2004) comienza con el diseño de una visión atractiva y desafiante definida con la participación de todos, y sigue con su ligazón a una estrategia de consecusión, la especificación de la visión en acciones, el mantenimiento de un espíritu optimista y la realización de pequeños pasos conducentes a éxitos repetidos. La principal característica del desarrollo organizacional es la concepción de un sistema al que hay que cambiar considerándolo un sistema y donde hay que mantener ligados el direccionamiento estratégico con los escenarios de actuación y sus actores. Evidentemente, se necesita una buena dosis de poder para implementar una cosa así. Probablemente, el psicólogo que trabaja en cualquiera de los campos que he revisado más atrás no necesita tanto poder como el que pretende lograr 
cambios sistémicos. Los psicólogos pueden recurrir a diversas fuentes de poder. Raven, Schwarzwald y Koslowski (2006) identificaron 11 tipos de influencia organizacional y los estudiaron en organizaciones israelíes. De ellos quiero referirme solo a dos. Uno es el fundado en la credibilidad, es decir, basado en la expertise del profesional. Esto, que se consigue con conocimientos y experiencia, pero también con el cultivo de una imagen, le da al psicólogo la capacidad de influir sobre decisiones organizacionales que pueden ser importantes. La otra fuente de poder es el estatus dentro de la organización, que implica acceso a recursos. El psicólogo generalmente tiene muy poco acceso a recursos. Si descubre que el personal se preocupa por la salud de su familia, con suerte, logrará que el gerente de recursos humanos utilice los medios financieros a su disposición para negociar con empresas prestadoras de servicios de salud tarifas cómodas para sus empleados. El desarrollo organizacional suele acoger visiones humanísticas y toda clase de gurus, pero no genera investigaciones científicas en el Perú.

\section{Consejería y coaching}

La quinta área definida por Flórez y Salas (2011), la de consejería, en la forma de coaching, es la de incursión más reciente por el psicólogo en las organizaciones. Este enfoque de consejería fue desarrollado en los Estados Unidos de la década de1990 por Thomas Leonard, quien aplicó el concepto deportivo de coaching en las organizaciones, poniendo énfasis en la lucha por mejorarse uno mismo, la persecución de metas y el pensamiento positivo (Peltier, 2009). De Australia vino después el coaching ontológico, con un énfasis en las comunicaciones, la emoción y el lenguaje corporal (Sieler, 2010). No tengo duda que se están aplicando también enfoques psicoanalíticos localmente. El ejecutivo puede ser referido por la organización en busca de un mejoramiento específico; por ejemplo, superación de problemas de interacción personal. $\mathrm{O}$ puede pedir el coaching por su cuenta sin que la empresa medie para nada. El psicólogo, a su vez, puede enfocarse en el mejoramiento 
del individuo en referencia específica a su entorno laboral o abordando la situación de la persona de manera más amplia y puede usar tests o no, dependiendo de la circunstancia. Parece que nadie ha evaluado la utilidad de este sistema en el Perú; a él le serían aplicables los paradigmas de evaluación de los efectos de la psicoterapia.

\section{Reingeniería de tareas}

La de reingeniería de tareas es una línea personal de trabajo que ilustra el esfuerzo acumulativo que puede desplegar el psicólogo organizacional sobre un tema, así como el empleo del método experimental, virtualmente desconocido en la psicología peruana. En 1999 el Ministerio de Salud estaba acosado por acusaciones de que las obstetrices y médicos presionaban a las mujeres a esterilizarse. El Population Council recibió una solicitud de la Agencia de los Estados Unidos para el Desarrollo Internacional de evaluación de la calidad de los servicios de planificación familiar a escala nacional. Usando diversas técnicas, que incluían el Test de Servicios, hice el diagnóstico y detecté casos de violación de derechos humanos que, pese a representar solo el 2,2\% de las mujeres atendidas, involucraban posiblemente a miles de mujeres (León, 1999). En ese proceso, descubrí un problema más frecuente que cualquier otro. Las obstetrices, esforzándose por satisfacer el derecho de la usuaria a recibir toda la información sobre los métodos anticonceptivos, empleaban una consejería que, paradójicamente, no era sensible a las necesidades de la usuaria. Con frecuencia le daban exceso de información irrelevante, mientras que la información relevante que ofrecían era incompleta. Algunas obstetrices, sin embargo, empleaban una estrategia interactiva de consulta; trataban de averiguar qué necesitaba la mujer y limitaban la entrega de información a lo relevante.

Para potenciar ese enfoque, disené una estrategia de consejería de cinco pasos basada en dos ayudas de trabajo. Un juego de 11 tarjetitas, referido a 11 métodos anticonceptivos, sería tirado sobre la mesa. Mediante ciertas preguntas, la obstetriz iría descartando, es decir, 
sacando de la mesa, los métodos (tarjetas) que no eran relevantes para la usuaria o que la usuaria rechazaba. Una vez que la mujer terminara de elegir un método, se le daría un folleto de cuatro páginas con información exhaustiva sobre ese método. No es fácil persuadir a un Ministerio para hacer un cambio de esta naturaleza, pero logré que el sistema fuera puesto a prueba en una intervención donde 12 regiones de salud del Perú aleatoriamente seleccionadas recibieron el tratamiento y 12 sirvieron de control. Descubrí que había una tendencia a que las obstetrices que ya desde antes entregaban un mejor servicio adoptaran la nueva estrategia y se observó que las obstetrices recapacitadas que usaban la nueva estrategia mejoraban considerablemente su calidad de atención, pero las obstetrices capacitadas que no usaban la nueva estrategia no se distinguían de los casos de control por la calidad de su servicio. Entrevistas posteriores revelaron que en la base de esta subutilización estaban las dudas de las obstetrices sobre su propia eficacia en el manejo efectivo del nuevo sistema (León, Ríos \& Zumarán, 2005; León, Ríos, Zumarán \& Bratt, 2003). La toma del Ministerio de Salud por fundamentalistas católicos rompió la continuidad de esta línea de trabajo en el Perú, pero en Guatemala diseñé un algoritmo para fortalecer la confianza de la obstetriz en el nuevo sistema al indicarle exactamente lo que debía hacer en 22 pasos. Una evaluación cuasi-experimental produjo evidencias de eficacia del nuevo sistema en dos departamentos mayas y dos departamentos ladinos, y la Estrategia de Consejería Balanceada fue adoptada como el modelo oficial de consejería por el Ministerio de Salud Pública de Guatemala (León y cols., 2005). El Population Council probó la Estrategia mediante sendos estudios en Kenya y Sudáfrica y la ha puesto al alcance del público internacional gratis y en tres idiomas a través de Internet (León, Vernon, Martin \& Bruce, 2008). También pertenece a esta sección un marco conceptual para evaluar el impacto de la introducción de un método anticonceptivo en el portafolio de las obstetrices. El modelo fue implementado en un cuasi-experimento pre-post con grupo de control en Jaén y Moyobamba (León \& cols., 2007a). 


\section{Psicología del consumidor}

La psicología del consumidor está en el traslape de la psicología con el márketing. El psicólogo del consumidor provee a sus clientes con información e interpretaciones sobre las percepciones, actitudes y comportamientos de los consumidores respecto a productos, servicios, o instituciones específicas y, en algunos casos, propone acciones para modificarlos. En el Perú, el psicólogo del consumidor presta ayuda a corporaciones industriales, comerciales y de servicios, así como a instituciones públicas y ONG; esto incluye, por supuesto, agencias de publicidad y empresas consultoras. El área también incluye el marketing político.

La psicología del consumidor se diferencia claramente de la psicología organizacional por tener a su objeto de estudio generalmente fuera de la organización, mientras que la última lo tiene al interior de la misma. Sin embargo, comparten un concepto, el de clima de servicio, que se puede abordar desde la psicología organizacional y desde la psicología del consumidor. El camino del progreso para el psicólogo del consumidor apunta a la conversión en empresario de los servicios ofrecidos. En cuanto a la competencia, esta no viene solo de los administradores especializados en marketing sino también de los antropólogos, quienes cada vez más son llamados por las empresas para aportar sus observaciones y explicaciones. Todavía no hay estudios que nos digan cuán preparado sale de las universidades peruanas el psicólogo de orientación cuantitativa que quiere trabajar en esta área, pero la opinión de los conocedores es que lo hace mejor preparado que el administrador o el ingeniero. Por un lado, tiene mayor disposición a preguntarse por los motivos de los comportamientos humanos más allá de lo obvio. Por otro, ahora conoce de análisis de datos mucho más que el psicólogo de décadas anteriores. Se le puede criticar, sin embargo, que sepa poco de negocios y le cueste pensar en términos estratégicos. Parece que la mejor senda de superación para él es hacer una maestría de administración con especialización en marketing. 
Los psicólogos de orientación cualitativa usan técnicas como la entrevista en profundidad, el focus group y la "antropología visual", que consiste en observaciones etnográficas. Así, para hacer un seguimiento del focus group en el que una mujer ha participado, pueden pasar un día en su hábitat, tomando nota de sus costumbres y hasta de la presencia de productos específicos en la cajonería de sus closets. Estos psicólogos aprecian la observación, pero entienden poco del carácter probabilístico de las ciencias sociales. Consideran que las mediciones cuantitativas pueden ser útiles para dimensionar ciertas variables pero de ninguna manera para profundizar en los significados de un tema.

Aunque alcancen a desarrollar un alto nivel de credibilidad en su área, los psicólogos de orientación cualitativa no pueden lograr los niveles de influencia del psicólogo cuantitativo con estudios de administración, que puede hablarle al gerente de márketing con mayor autoridad. Esta falta de poder puede tener consecuencias inimaginables. Considérese la quiebra de una compañía nacional de cerveza un par de décadas atrás. El psicólogo presentaba a la gerencia de márketing evidencias cualitativas de que los consumidores estaban notando una caída importante de la calidad de la cerveza de su marca y recomendaba acciones correctivas inmediatas. Sin embargo, no logró persuadir al gerente de la conveniencia de abandonar la crencia de que "el borracho toma cualquier cosa”. Tal vez otro habría sido el caso si hubiese podido mostrarle números y hablarle del retorno de la inversión.

Ciudad de los Reyes, de los Chávez, de los Quispe (Arellano \& Burgos, 2010), que se publicó originalmente en el año 2000, es sin duda alguna el libro más influyente que ha escrito jamás un psicólogo peruano de cualquier especialidad. Ha vendido millares de ejemplares y ha influido en las ciencias sociales peruanas al revalorar al provinciano en Lima, así como en la administración de marketing al presentar una segmentación del consumidor peruano. Revisada en el año 2006 en Perú y México, ella consiste en seis segmentos psicosociales definidos por el estilo de vida: sofisticados $(7.7 \%)$, progresistas $(20.8 \%)$, modernos $(25.3 \%)$, adaptados (19.8\%), conservadores (19.1\%) y resignados $(7.2 \%)$. 
Estos segmentos fueron identificados mediante encuestas y la técnica estadística del cluster analysis y fueron refinados y consistenciados con información de origen cualitativo. No tienen relación con los estilos de vida medidos por cuestionarios estándar como el utilizado por Campos (2009) en Huánuco. La influencia de la segmentación de los consumidores propuesta por Arellano se puede apreciar en su alcance más allá del márketing o la psicología del consumidor; ahora resulta que Inca Kola la usa como herramienta de psicología organizacional. A despecho de sus sofisticados orígenes, sin embargo, la segmentación de Arellano aún carece de sustentación científica, pues no está publicada con el detalle suficiente ni en una revista científica que cuente con un consejo editorial solvente, independientemente de que se dirija a psicólogos o administradores. En Estados Unidos o Europa, los psicólogos del consumidor, trátese de consultores o profesores, primero publican en revistas como el Journal of Consumer Research, International Journal of Consumer Studies, Journal of Marketing Research, Journal of Consumer Behaviour, etc. y recién entonces se dirigen al público general. Arellano tiene el talento y los recursos para publicar estudios demostrativos de la robustez de su segmentación, construir tests adecuados para medir los constructos a nivel individual, y analizar la relación entre tales mediciones y el comportamiento del consumidor. Los psicólogos cualitativos peruanos del consumidor tampoco publican en revistas académicas.

De allí que los trabajos relevantes que pude encontrar en la literatura científica tengan autores que están lejos de concebirse a sí mismos como especialistas en psicología del consumidor. Ocrospoma (2003) constató que los alumnos de primer año y los de último ańo de una universidad coincidían al valorar ciertos rasgos de los profesores como positivos y otros como negativos. Siendo los alumnos consumidores de los servicios académicos del profesor, este puede concebirse como un estudio del consumidor. También clasifiqué en psicología del consumidor un trabajo de Orellana y cols. (2008) sobre las representaciones sociales del psicólogo que tenían los profesores de la educación básica pública y privada de Lima y provincias. Los profesores son consumidores potenciales de los servicios escolares que brinda el psicólogo y un 
estudio de la imagen que los maestros tienen del psicólogo también es un estudio del consumidor. Por allí hay un estudio descriptivo de actitudes hacia la compra de intangibles a través de Internet (Pérez, 2011).

\section{Psicología comunitaria}

Tanto la psicología organizacional como la del consumidor que se practican en el Perú provienen virtualmente enteras de Estados Unidos, donde se originaron en el marco de una sociedad con valores individualistas. La psicología comunitaria peruana, en cambio, se ha desarrollado a base de contribuciones oriundas y como un esfuerzo que privilegia explícitamente valores colectivistas. La psicología comunitaria peruana combina el enfoque de la psiquiatría social con el de la abogacía política. La psiquiatría social apareció en el Perú en la década de 1960, cuando el psiquiatra concluyó que la prevención en el área de la salud mental le demandaba salir del consultorio y conocer la comunidad circundante (Caravedo, Rotondo \& Mariátegui, 1963). La conclusión de que se requería algo más que el mero cambio de conducta de los individuos — que se necesitaba un soporte comunitario- tuvo como resultado el establecimiento de departamentos de psiquiatría comunitaria en los principales hospitales mentales de Lima. En estos hospitales terminaron de formarse muchos psicólogos. La psicología comunitaria peruana nace siguiendo los pasos de la psiquiatría social, pero se diferencia de ella al concebir la necesidad de producir transformaciones sociales trascendentes como requisito para la mejoría de la salud mental global y al adoptar la abogacía política como un eje central de su discurso. Considérese la siguiente declaración de uno de los directores del Consultorio Psicológico de la Universidad de San Marcos: "La Universidad no solo es un centro de cultura superior que investiga y prepara profesionales altamente calificados, sino que su misión también es preparar hombres y mujeres con conciencia crítica de su rol social, comprometidas con su etapa histórica, y al servicio de las mayorías" (Amorós, 1983). 
Carmen Pimentel, una de las fundadoras de la psicología comunitaria peruana, propuso cambios en "las condiciones de desarrollo del conjunto de la sociedad" y Vallejos y Montero, también en un congreso, reconocieron la existencia de una relación muy cercana entre nuestros niveles de salud y el contexto político y económico en que vivimos. Así, ahora existen en el Perú concepciones de la población que sufre problemas de salud mental en situación de pobreza como víctimas que deben ser convertidas en ciudadanos (Pezo, Velásquez, Valz-Gen \& Pareja, 2008) y los temas de salud mental tienden a ser reedefinidos como asuntos "de ciudadanía y derechos humanos" (Velásquez, 2007a). Este tipo de visión política estuvo presente en los inicios de la psicología comunitaria norteamericana (Rappaport, 1977) pero no marca con la misma fuerza su discurso, probablemente porque en Estados Unidos la diversidad cultural, la pobreza y la exclusión no alcanzan la severidad que han adquirido en nuestro país, y los norteamericanos no han sufrido recientemente las heridas de una guerra interna.

La psicología comunitaria es aplicada topográficamente, con claras delimitaciones de territorio; por ejemplo, a un vecindario, un municipio, una ciudad devastada por un sismo, etc. Hay, sin embargo, dos excepciones al criterio topográfico de comunidad, una en la teoría y la otra en la práctica. Se concibe la "comunidad imaginada" como aquella construida a partir de referentes identitarios, los vínculos afectivos y los significados y símbolos compartidos, como sería el caso de los ayacuchanos migrados a Lima que Arguedas describió en "Todas las sangres”; otro caso podría ser el de las familias de los trabajadores de una empresa que viven apartadas unas de otras. Y la psicología comunitaria abandona el criterio topográfico cuando se confunde con la psicología de la salud al incluir actividades más genéricas, como los programas de salud pública en los que trabajan psicólogos tratando de prevenir el abuso de drogas o los embarazos indeseados sin limitarse a un ámbito geográfico estrecho. Otra característica de la psicología comunitaria peruana es que se considera a sí misma una disciplina en construcción y al mismo tiempo parte de una corriente latinoamericana (Velásquez, Cueto, Rivera \& Morote, 2011). 
Los marcos teóricos presentados por Pezo y cols. (2008) y dos textos de Velásquez (2007a; Velásquez \& cols., 2011) son expresiones netas de una psicología clínica de orientación psicoanalítica. Me pregunto si este enfoque es capaz de realizar la psicología comunitaria que Maritza Montero (1984) concibió como "la rama de la psicología cuyo objeto es el estudio de los factores psicosociales que permiten desarrollar, fomentar y mantener el control y poder que los individuos pueden ejercer en su ambiente individual y social para solucionar problemas que los aquejan y lograr cambios en esos ambientes y en la estructura social". Cuando se habla del estudio de factores psicosociales en una perspectiva científica se supone que uno trabaja con variables claramente delineadas para llegar a conclusiones. No veo a la psicología clínica-comunitaria orientada a la investigación en este sentido. Hay estudios valiosos, como aquellos sobre las reminiscencias y secuelas de la violencia sexual durante la guerra interna del siglo pasado en Huancavelica (Cárdenas \& cols., 2005; Velásquez, 2007b), pero también una resistencia a la abstracción de variables bajo la idea que no se debe romper la integralidad con la que ocurren los fenómenos sociales. El encuadre metodológico psicoanalítico parte de la intuición más que de la observación, se basa en el análisis lingüístico y culmina en el afronte holístico de sus materiales. Tal epistemología hace difícil el desarrollo de redes nomológicas claramente diferenciadas y de aplicación general; un trabajo notable como el de Matos y Lens (2009) sobre cultura escolar, donde las variables psicológicas son definidas con precisión y medidas objetivamente y las hipótesis son sujetas a prueba empírica, resulta impensable para una psicología clínica-comunitaria psicoanalítica. Es por este encuadre intuitivo que la psicología clínicacomunitaria peruana se distingue claramente de la psicología social peruana, que se basa más en la observación. La psicología social puede coincidir en sus motivaciones políticas con la comunitaria, pero trata de definir y medir sus variables y poner a prueba sus hipótesis. De otro lado, mi comentario no representa una crítica general a los enfoques cualitativos de recolección de datos. Hay maneras objetivas de manejar información cualitativa (Strauss \& Corbin, 1998). 
Los psicólogos comunitarios llaman investigación-acción a sus actividades, consistentes en la realización de un diagnóstico cualitativo a partir del cual se traza una estrategia de promoción o solución de problemas de salud mental y otros que, de acuerdo al discurso, deben ser definidos por la comunidad. Yo no he visto eso en la práctica. La Universidad Católica envió brigadas psicológicas al suroeste peruano luego del terremoto de 2001 (Kudó \& cols., 2005) y a Pisco, Chincha, Ica y Huancavelica luego del de 2007 (Thorne, Velásquez \& Argumedo, 2008). Consideraron que una intervención temprana, que brindara soporte y movilizara los recursos de la misma población, constituiría una labor preventiva de reducción del impacto psicológico perturbador de la experiencia e hicieron esfuerzos para que los efectos positivos duraran. Pero el esquema de intervención ya estaba definido antes que las brigadas psicológicas tomaran contacto con la comunidad, lo cual me parece muy razonable dada la situación de urgencia. Estos textos prácticos están tan bien escritos como los teóricos, pero exhiben un lenguaje más sencillo.

De otro lado, hay trabajos de psicología comunitaria que no están marcadas por el psicoanálisis. Malvaceda (2010) abordó las formas andinas de sufrimiento tras la violencia política y Tarazona, Jerí de Pinho y Bellido (2011) aplicaron un enfoque ordinario de estudio de casos al proceso de formación de promotores comunitarios. Cedro (2010) ha formado una red de 3000 instituciones en Lima y 1000 en provincias a las que ha involucrado en acciones de prevención del consumo de drogas, poniendo énfasis en valores democráticos, derechos humanos y preservación del medio ambiente. Su estrategia de intervención es la de generar coaliciones que dinamicen las fuerzas positivas existentes en la comunidad y las pongan al servicio del desarrollo comunitario y el control social; por ejemplo, que el tendero entienda el daño que produce vendiendo alcohol a menores de edad y el sacerdote dirija sus sermones a temas sociales. Una tarea pendiente es la de publicar los resultados de sus intervenciones. Otra, la de articular más explícitamente sus esquemas de intervención y evaluarlos con las metodologías adecuadas de evaluación de intervenciones. Finalmente, se necesita mejor articulación entre el discurso y la práctica. En su manual de salud comunitaria, 
Lara (2005) propone la realización de un diagnóstico integral de los problemas de salud de la comunidad, pero da la impresión que al llegar a cualquier comunidad ya sabe que no encontrará un problema más importante que el de prevención del abuso de drogas.

\section{Psicología social}

La psicología social, una subdisciplina orientada a la investigación, desarrollo conceptual, e intervenciones en pro del bienestar público, está ubicada en el traslape con las ciencias sociales. Aquí la relación es de dos vías; es decir, los psicólogos toman y dan. En el año 2002 el Premio Nobel de Economía fue entregado al psicólogo Daniel Kahneman por sus aportes al entendimiento de la toma de decisiones bajo incertidumbre y, en el Perú, ha tenido que ser un psicólogo quien descubra que la riqueza, contra la creencia de la mayoría de economistas, es mayor en el sur que en el norte del país (León, 2012c). En el traslape con las ciencias políticas están los temas de identidad social y ciudadanía. Esta es la subdisciplina psicológica con mayor potencial de desarrollo científico en el país, tanto por la diversidad de sus temas como por el potencial paradigmático que tienen algunos de los aportes. Aunque existen aportes aislados (v.g., Espíritu, 2009), los estudios son agrupables en los siguientes temas principales.

\section{Procesos urbanos}

Hay tres procesos urbanos muy dinámicos que están siendo abordados por la psicología social en el Perú: el tránsito vehicular, la violencia juvenil y la comunicación masiva. Ponce, Bulmes, Aliaga, Delgado y Solís (2006), en un análisis de autorreportes de los rasgos de personalidad que se ponen de manifiesto en situaciones de tránsito vehicular, observaron patrones de mejor ajuste en choferes interprovinciales que entre choferes particulares, taxistas y microbuseros de Lima. En el tema de la violencia, Ponce (2003) analizó la consistencia y estructura interna de un cuestionario de comportamientos antisociales-delictivos 
de jóvenes y reportó correlaciones negativas, pequeñas pero significativas, con su satisfacción familiar. Carpio y Alay (2012) han empleado una teorización ecológica que distingue las influencias del micro y el macrosistema en el comportamiento antisocial. En el tercer tema, Montero (2008) combinó métodos cuantitativos y cualitativos en un análisis psicosocial del discurso de la prensa sensacionalista peruana y las actitudes de los lectores según su género. Un análisis más focalizado de la prensa sensasionalista abordó las recientes elecciones municipales de Lima (Malvaceda \& cols., 2012).

\section{Pobreza}

En Lima, Tarazona (2005) halló que la pobreza, medida por las condiciones de habitabilidad de la vivienda, tenía relaciones complejas con la satisfacción personal; se puede notar en sus tablas y figuras que la satisfacción personal crece con la mejor habitabilidad, pero incrementos de la última más allá de un cierto nivel no se acompañan con mayor satisfacción con la vida. Ventura (2010) ha completado un estudio de casos bastante notable y original sobre reducción de la pobreza de familias rurales atribuible a la presencia de una empresa en la zona. El foco estuvo en los efectos de las actividades rentables y de responsabilidad social de dos empresas financieras y dos extractivas en la sierra y selva. En contraste con la metodología cualitativa de los psicólogos comunitarios que se centra en los eventos subjetivos, Ventura la aplicó a los comportamientos y productos sociales utilizando técnicas de análisis inductivo y procedimientos iterativos. Encontró que los procesos de reducción de la pobreza de las familias observados en el estudio no apoyaban al modelo de desarrollo basado en activos físicos (De Soto, 2000; De Soto, Ghersi \& Ghibellini, 1986) sino, más bien, a los modelos de acceso a los mercados (Prahalad, 2005) y de desarrollo de capacidades (Sen, 2002). El último refiere el desarrollo humano más al ser y hacer de las personas que al tener, pues concentra su concepción en el desarrollo de las potencialidades humanas, más allá de los medios de vida o bienestar material. Es decir, salir de la pobreza es una cosa y lograr desarrollo humano puede ser otra. 


\section{Emprendedorismo}

En su revisión de la literatura sobre el potencial emprendedor juvenil en Latinoamérica, Tueros (2007) citó estudios que advierten la emergencia de un grupo importante de jóvenes que optan por la empresa y el autoempleo. Ellos provienen de estratos sociales más afluentes y tienen contactos sociales que les permiten un mayor acceso a recursos críticos para la consolidación de sus emprendimientos que los jóvenes de estratos pobres. Considerando que el apoyo a los más pobres debe comenzar en la instrucción secundaria revelándoles la naturaleza de las oportunidades de autoempleo, Tueros, Gutiérrez y Germans (2009) implementaron y evaluaron en Lima el sistema de capacitación Conozca de Empresa desarrollado por la OIT. Los sujetos fueron 239 estudiantes que recibieron la intervención y 113 que no la recibieron. Los resultados sugieren beneficios de la capacitación, aunque no queda claro si hubo asignación de sujetos, de salones de clase, o de escuelas a las condiciones de tratamiento y si este fue un proceso aleatorio. Siendo la orientación futura y la creatividad rasgos clave para el establecimiento de planes y metas y la formulación de nuevas maneras de enfrentarse a los problemas, los estudios de Herrera y Lens (2009) y Martínez (2009) sobre orientación temporal y de Caycho (2010) sobre estilos de pensamiento son relevantes al emprendimiento. Con mayor especificidad, Loli, Dextre, Del Carpio y De la Jara (2010) y Loli, Aliaga, Del Carpio, Vergara y Aliaga (2011) abordaron el rol de la creatividad, y Portocarrero, Mayorga y García (2010) usaron el test de coeficiente empresarial de la Northwestern Mutual Life Insurance Company. También son relevantes el estudio de valores de Escurra (2003) y el de Vicuña, Hernández y Ríos (2004) sobre motivación de logros. Finalmente, tienen incidencia en el tema los estudios de Paredes (v.g., Paredes, De Miguel, Carbajal y Laguna, 2004). Paredes y cols. (2007) hallaron pobre conocimiento de los pobladores de en Caraz, Ancash, sobre la demanda de sus productos y Paredes, Hernández, Vicuña, Arias y Rivera (2009) evaluaron los resultados de un taller de revaloración de sus productos culturales para la comercialización comparando una prueba de entrada y una de salida. 
Hay una necesidad imperiosa de fortalecer la evaluación de intervenciones sociales en la psicología peruana. Evaluar adecuadamente una intervención demanda la aplicación de conocimientos avanzados de metodología experimental y estadística, como los que revisaron Shadish y Cook (2009) en su reciente capítulo del Annual Review of Psychology. Para una aplicación práctica, puede verse León, Lundgren, Sinaí y Jennings (2011).

\section{Identidad social}

Oswaldo Orellana (2005) reportó mayor resentimiento entre personas autoclasificadas como cholos serranos o serranos blancos que entre aquellas autoclasificadas en otros estereotipos raciales. Jorge Bruce (2007) publicó un libro de mucho impacto popular en el que presenta sus observaciones sobre el racismo y menciona el modelo matemático para cholear de Twanama, que incluye los rasgos físicos, el nivel socioeconómico, el nivel educativo-lingüístico y la calidad de migrante. En un grupo de estudiantes universitarios, Ramón León (2010) halló que los peruanos eran vistos como creativos y trabajadores, pero también como corruptos, acomplejados y envidiosos; la influencia de la herencia colonial no fue considerada como muy elevada. En esta área ha emergido una línea personal de investigación que parte de conceptos internacionales de vanguardia sobre identidad social y relaciones intergrupales para desarrollar conceptos propios en torno a la identidad nacional (Espinosa, 2010). Lo que vertebra la obra de Espinosa es la finalidad última de aportar activamente al desarrollo de una identidad nacional positiva. Advirtiendo que la pertenencia o identificación con diferentes grupos étnicos y sociales dan al individuo perspectivas diferentes sobre el "ser peruano", propone identificar el núcleo representacional compartido por los diversos grupos étnico-sociales e iniciar procesos de construcción o reforzamiento de una identidad común contenedora de autoconceptos positivos y sustentada en el respeto a las diferencias. Por ejemplo, Espinosa, Calderón-Prada, Burga y Güimac (2007) dieron varios cuestionarios a 81 residentes limeños de clase media y reportaron 
que ellos veían a los peruanos como trabajadores, alegres, capaces, conformistas y corruptos. Los mestizos aparecían con el perfil más parecido al del peruano en general, excepto que eran vistos como incumplidos más que como capaces. En cambio, el andino emergía como triste, trabajador, atrasado, solidario y conformista; y el blanco, como desarollado, individualista y exitoso, además de corrupto y capaz.

El estereotipo del mestizo emerge entonces como el posible núcleo de la identidad del peruano, aunque una dificultad estriba en el sesgo negativo que se observa contra la diversidad racial (Genna, Espinosa \& Páez, 2010). Habitantes de una zona de extrema pobreza urbana (Callao) presentaron estereotipos similares (Pancorbo, Espinosa \& Cueto, 2011). En su búsqueda de imágenes que contribuyan al fortalecimiento de la identidad nacional, Rottenbacher y Espinosa (2010) encontraron que es necesario recurrir a la historia lejana, más que a la cercana, como fuente de un concepto positivo del Perú. Mientras más cercano es el evento histórico, peor valorado es. Lo mismo ocure con los personajes históricos. Lo que aparece en el presente como posible elemento integrador positivo es la culinaria peruana (Espinosa \& Calderón-Prada, 2009). También se ha analizado las bases ideológicas del racismo, el sexismo y la homofobia (Rottenbacher, Espinosa \& Magallanes, 2011). En general, los trabajos podrían conseguir un mejor equilibrio si atendieran a la crítica que Martín Tanaka aplicó al libro de Bruce (2007): necesitan muestras más heterogéneas que estudiantes de universidades privadas de Lima para generalizarse al país.

\section{Instituciones y política}

Carlos Franco (1980) fundó la psicología política peruana alrededor del concepto de participación cuidadana activa. Tal como Arenas (2007) concibe la de hoy, el estudio de los valores y comportamientos que sostienen a la democracia deben ser de interés primordial. La educación puede favorecer la formación de valores sustentadores de democracia (Reátegui \& Frisancho, 2012) pero también puede propulsar la violencia (Frisancho \& Reátegui 2009). Frisancho (2010) 
ha estudiado la corrupción en el poder judicial peruano; ella presentó unas viñetas a jueces locales y evaluó la moralidad de sus respuestas en la perspectiva de la teoría psicológica del dominio. Vicuña y cols. (2006) estudiaron la disposición a la corrupción en estudiantes universitarios y Arenas, Hernández, Matalinares y Rivera (2004), en un estudio sobre representaciones de ciudadanía y confianza en la democracia, reportaron una concepción más abstracta y menos egoísta de la democracia entre estudiantes universitarios que entre escolares de secundaria. Falta por verse si la diferencia es atribuible solo a procesos evolutivos; sería interesante comparar universitarios con jóvenes de su misma edad que no están en la universidad para determinar en qué medida contribuye a los resultados la autoselección de quienes accedieron a estudios superiores. El mayor desafío para el psicólogo en esta área está en el estudio de los procesos democráticos como procesos y los comportamientos humanos que entrañan. El desafío lo aceptó Ventura (2003) cuando abordó el tema de la democratización de los recursos públicos y escribió una monografía sobre las metodologías y herramientas de presupuesto participativo basado en experiencias iniciadas espontáneamente por algunos alcaldes. Sus materiales fueron usados como insumos de la Ley de Presupuesto Participativo del Perú del año 2003. Los estudios de casos de Ventura de implementación en municipios de diversos puntos del país sugieren que tanto el diseño como los resultados del presupuesto participativo dependen de las intenciones de los actores y de las condiciones pre-existentes. Los exitosos casos de Ilo (Ventura, 2004a) y Villa El Salvador (Ventura, 2004b) sugieren la importancia de una tradición participativa previa, mientras que el de Huaccana, en Cusco (Ventura, 2004c), puede atribuirse al liderazgo ejercido por el alcalde quechua. Otros psicólogos abordan los procesos políticos de manera diferente. Espinosa (2008) analizó el rol de las emociones en las elecciones peruanas de 2006; Ferrándiz, Ibáńez y Espinosa (2011) midieron los niveles de agresión, prejuicio y racismo que se mostraron en la redes sociales limeñas (facebook o twitter) durante la campańa electoral de 2011; y Rottenbacher (2012) utilizó un modelo de ecuaciones estructurales según el cual la intolerancia 
a la ambigüedad y la necesidad de cierre cognitivo ejercen una influencia directa sobre el autoritarismo de ala derecha.

\section{Bienestar personal}

Alarcón (2006) ha hecho esfuerzos por medir la felicidad y la ha encontrado relacionada positivamente con la extraversión y negativamente con el neuroticismo. Yamamoto, Meza y Ríos (2005) han introducido una perspectiva original en el área del bienestar personal, comenzando con un estudio en la Amazonía donde derivó sus categorías conceptuales de las respuestas de los pobladores en lugar de aplicar conceptos originados fuera del Perú, y aplicó a estas categorías sui generis análisis exploratorios de factores o factor analysis. Antropólogos y sociólogos (Altamirano, Copestake, Figueroa \& Wright, 2003) ya habían señalado la necesidad de tomar en cuenta la identidad cultural local, pero Yamamoto dio el paso crucial de integrar el afronte émico de la antropología con el enfoque cuantitativo psicológico. Ciertas metas de bienestar fueron identificadas con el enfoque émico y confirmadas con el factor analysis en un corredor migratorio que, pasando por Huancayo, va desde Huancavelica hasta Huaycán. Los rasgos de personalidad identificados en esa población fueron solo tres y no se correspondían exactamente con los Big Five. "Mosca", cuyo opuesto es "ahuevado", combina intelecto, estabilidad y conciencia; "buena onda" integra extraversión y agradabilidad; y "cálido" integra agradabilidad y conciencia. En el mismo estudio, Yamamoto y Feijoo (2007) identificaron los valores de individualismo y colectivismo y un factor unidimensional de recursos materiales y no materiales. Con Lazarte (Yamamoto, Feijoo \& Lazarte, 2008), midieron las relaciones directas e indirectas que existían entre todas estas variables usando ecuaciones estructurales y encontraron a la población satisfecha con lo logrado en términos de formación de una familia pero no respecto al sitio donde vive ni el nivel alcanzado de desarrollo. Los análisis fueron extendidos a Bangladesh y Tailandia y han tenido impacto internacional (v.g., Copestake, 2009). Superación familiar, tener buenas relaciones 
con los demás y superación personal son las necesidades que identificó Rojas (2012) entre operarios de una mina andina, es decir, distintas a las identificadas por Yamamoto, Feijoo \& Lazarte (2008). La pregunta que sigue es si cada microsociedad tiene un sistema sui generis de necesidades o hay necesidades universales que las subordinan.

\section{Efectos de la geografía}

Miljanovich, Martina, Huerta, Torres y Camones (2010) reportaron mayores índices de violencia familiar en Loreto que en cualquier otra región política peruana. Arenas y cols. (2011) encontraron un nivel de desarrollo moral que era menor en jóvenes de Pucallpa que de Lima, Ica, Chimbote y Trujillo. Blitchtein-Winicki y Reyes-Solari (2012) compararon la violencia de género contra la mujer en el territorio nacional; se observa en sus datos que, excluyendo Lima Metropolitana (12\%), hay más violencia en el resto de la costa urbana (14.6\%) que en la rural $(9.7 \%)$, en la sierra urbana (18.9\%) que en la rural $(14.4 \%)$, y en la selva urbana (17.8\%) que en la rural (16.3\%).

La mayoría de estudios psicológicos peruanos comienzan y terminan con el reporte de resultados como estos, sin la realización de un esfuerzo conceptual por darles sentido y lograr un perfeccionamiento de las ideas mediante el contraste con nuevos datos. Este autor tuvo la suerte de quedar con tiempo disponible para volver a un tema y perseguirlo hasta darle solución. Un cuarto de siglo atrás había conjeturado mayor autonomia de la mujer sureña versus mayor sometimiento tradicional al marido por la norteńa para explicar variaciones en el deseo fecundatorio de las mujeres peruanas (León, 1984). Un análisis de datos de la Encuesta Demográfica y de Salud (ENDES) Continua Perú 2004-2008 apoyó esta hipotesis al revelar un crecimiento significativo de norte a sur del control de la mujer sobre el ingreso del cónyuge y las decisiones adquisitivas hogarenas. Estas relaciones no eran explicadas por variables correlacionadas, como la etnicidad indigena, poder material/informacional de la mujer, diferencia de edad con el marido, o que trabajara por dinero (León, 2011). Un estudio de datos de 46 países 
sugirió que la autonomía de la mujer es determinada por un rasgo de personalidad, la asertividad, con independencia de su edad, educación y variables culturales (León, 2012a). Un análisis de la ENDES Perú 2000 confirmó que el poder doméstico de la mujer crece de norte a sur en el Perú, mientras que el deseo de hijos presenta una tendencia opuesta, de manera que la relación negativa entre poder y deseo decae al incrementarse la latitud absoluta. ¿’Por qué un rasgo de personalidad tendría que estar relacionado a la latitud? En la era de Internet fue fácil el desarrollo de una teoría psicobíogreográfica según la cual la última causa sería la radiación ultravioleta (RUV). La RUV está estrechamente correlacionada con la latitud, pues decrece desde el ecuador hasta los polos y determina el éxito de la fabricación de vitamina $\mathrm{D}$ por la piel y retina. Esta vitamina es causa de diferenciación sexual, ya que promueve la síntesis de hormonas sexuales; es decir, hace más masculinos a los hombres y más femeninas a las mujeres (León, 2012b).

En paralelo había estado analizando la misma base de datos para averiguar si se incrementaban la riqueza del hogar y la educación de la mujer con la latitud absoluta en el Perú. Al confirmar la hipótesis, concluí que ambos, riqueza y educación son determinados por el nivel de inteligencia de la población, pues no pude imaginar otra variable más relevante; el poder doméstico de la mujer solo explicaba la riqueza en la región yunga. En ese momento solo disponía de la teoría evolucionaria de la inteligencia (Rushton, 1985, 2000) para explicar los resultados, así que asumí una diferenciación genética resultante de procesos adaptativos al clima y la altura en la población peruana milenios atrás. Pero, al descubrir la influencia de la RUV, recordé cómo me habían impresionado los trabajos de Zajonc décadas atrás y propuse una explicación alternativa incorporando a la teoría psicogeográfica dos nexos más: (a) la producción de hormonas sexuales determina el tamaño de las familias y (b) mientras más pequeńa es la familia, mayor resulta la inteligencia del niño, pues esta depende de la calidad del ambiente intelectual hogareño. Ese ambiente se deteriora con el incremento de hermanos, especialmente a edades más tempranas (Zajonc \& Bargh, 1980; Zajonc \& Markus, 1975; Zajonc \& Mullally, 1997; Zajonc \& Sulloway, 2007). 
La nueva teoría (León, 2012c) predice mayor cociente intelectual y puntajes más altos en las pruebas educacionales PISA del norte al sur peruano. La teoría permite entender los hallazgos de Arenas y cols. (2011) en Pucallpa considerando que el desarrollo moral está ligado al desarrollo intelectual; es posible que sea la región selvática del Perú la que recibe las mayores dosis de RUV, un retardador del desarrollo intelectual a través de su influencia sobre el tamaño de la familia.

Analicé la misma base de datos una vez más tratando de explicar mi antiguo hallazgo de un consumo de sustancias psicoactivas que era mayor en el sur que en el norte peruano (León, 1987). Teniendo en cuenta que la vitamina $\mathrm{D}$ se relaciona también con la producción de dopamina y serotonina, formulé la hipótesis de que la salud mental se deteriora con la distancia al ecuador. De acuerdo con lo esperado, hallé que la violencia física y psicológica ejercida por esposos y padres aumentaba con la latitud absoluta en el desierto del Pacífico, la estepa serrana, la puna y la ecorregión yunga, aunque no en la Amazonía (León, 2012d). La teoría psicobiogeográfica explica la menor violencia en ámbitos rurales que urbanos que se ve en los datos de BlitchteinWinicki y Reyes-Solari (2012): la población urbana desarrolla la mayor parte de sus actividades bajo techo y, por ende, recibe menores dosis de RUV que la rural. De otro lado, el hallazgo de Miljanovich y cols. (2010) de mayores niveles de violencia en Loreto que en cualquier otra región política del país parece contradecir mi reporte de mayor violencia en el desierto del Pacífico que en la Amazonía (León, 2012d). Pero el último hallazgo se obtuvo solo una vez que los efectos de otras variables fueron controlados. Además yo analicé los datos de la ENDES 2000, que incluía ítems sobre comportamientos positivos del esposo, mientras que Miljanovich y cols. (2010) analizaron la ENDES 2007 2008, que no los incluía. Otra posibilidad es que lo afectado por la latitud sea el componente positivo de la afectividad, no el negativo.

Teniendo en cuenta que solo una teoría psicológica, la evolucionaria de Rushton (1985, 2000), establece relaciones entre la latitud y un conjunto tan amplio de efectos psicológicos, se puede esperar que la teoría psicobiogeográfica genere pronto investigaciones internacionales. 


\section{Conclusiones}

Este artículo describió y evaluó cuatro subdisciplinas de la psicología peruana. Las siguientes son las conclusiones por subdisciplina:

1. Un desafío para el psicólogo organizacional es ajustar sus buenas prácticas a la evidencia científica; aquellas estudiadas en Estados Unidos o Europa no son necesariamente relevantes a toda empresa y población local.

2. La psicología del consumidor tiene impacto popular, pero sus cultores, tanto cualitativos como cuantitativos, no divulgan sus métodos y hallazgos con rigurosidad.

3. Las contribuciones de la psicología comunitaria podrían fortalecerse si sus hipótesis de trabajo de origen psicoanalítico, $\mathrm{u}$ otras perspectivas, fuesen formuladas con mayor nitidez $\mathrm{y}$ sometidas a metodologías convencionales de evaluación de intervenciones.

4. La psicología social peruana está contribuyendo al conocimiento de la realidad nacional y presenta aportes originales en reducción de la pobreza, identidad nacional, bienestar personal. y efectos de la geografía.

Una de las cosas que me ha sorprendido gratamente en la literatura revisada es la creciente utilización de ecuaciones estructurales para establecer relaciones de causalidad distinguiendo efectos directos e indirectos. Por el lado negativo está la virtual ausencia del método experimental fuera de mis propios trabajos. Los experimentos obligan a delinear con máxima claridad las hipótesis y proporcionan respuestas a cuestiones de causalidad que los malabares estadísticos de los estudios correlacionales, incluidas las ecuaciones estructurales, a veces distorsionan. Al diseñar un experimento, el psicólogo es proactivo, controla sus variables, actúa sobre la realidad y así la conoce mejor.

También he visto con agrado que la Revista de Psicología, así como hasta hace poco la Revista de Investigación en Psicología, hayan mantenido una actividad constante durante décadas y sean asequibles por Internet. 
Sería deseable que las otras revistas psicológicas nacionales se esfuercen por mantener una actividad predecible y pongan sus artículos en el ciberespacio. De otro lado, me ha sorprendido que haya tan poco trabajo sobre diferencias de género pese a la importancia de esta variable. Yo nunca he sido testigo de diferencias tan sistemáticas como las que observé entre los valores individualistas de los adolescentes y colectivistas de las adolescentes en mi estudio del siglo pasado (León, 1996). Me extraña que no se abunde más en esto. Otra variable que brilla por su ausencia es la de confianza. Sin confianza no puede haber democracia (Sullivan \& Transue, 1999) ni procesos organizacionales eficientes (Kramer, 1999). Pero estoy seguro que estas ausencias son subsanables en el mediano plazo. Considerando la juventud, preparación y talento que he encontrado entre los psicólogos peruanos, creo que el futuro de las psicologías del área social-organizacional en nuestro país está en buenas manos.

\section{Referencias}

Alarco, M. B. (2010). Conceptual and empirical similarities and differences between job insecurity and employability: A test in Perú. Tesis doctoral. Leuven, Bélgica: Katholieke Universiteit Leuven. Alarcón, R. (2006). Desarrollo de una escala factorial para medir la felicidad. Interamerican Journal of Psychology, 40, 95-102.

Altamirano, T., Copestake, J., Figueroa, A. \& Wright, K. (2003). Poverty studies in Peru: Towards a more inclusive study of exclusión. WeD (Wellbeing in Developing Countries ESRC Research Group) Working Paper 05. University of Bath.

Amorós, V. (1983). Reflexiones sobre la labor profesional del psicólogo clínico. Lima: COPSI.

Arellano, R. \& Burgos, D. (2010). Ciudad de los Reyes, de los Chávez, los Quispe. Lima: Planeta.

Arenas, C. A. (2007). La psicología social: Entre la acción social comprometida y el asistencialismo. Revista de Investigación en Psicología, 10, 157-166. 
Arenas, C. A,, Hernández, H., Matalinares, M. L., Rivera, J. C. (2004). Representación de ciudadanía y la confianza en la democracia según el nivel educativo en jóvenes de 18 a 23 años en Lima Metropolitana. Revista de Investigación en Psicología, 7(1), 27-38. Arenas, C., Matalinares, M., Montero, V., Malvaceda, E., Rivera, I. \& cols. (2011). Representaciones sociales de la corrupción y la violencia y su relación con la reflexión socio moral en jóvenes de zonas urbanas y rurales de diversas regiones del Perú. Revista de Investigación en Psicología, 14, 165-185.

Arenas, C. \& Montero, V. (2009). La agenda psicosocial en Perú: Autopercepción de logros, representación de eficacia social y responsabilidad social. Revista de Investigación en Psicología, 12, 101-113.

Argumedo, D., Díaz, K., Calderón, A., Díaz-Morales, J. F. \& Ferrari, J. R. (2005). Evaluación de la confiabilidad y la estructura factorial de tres escalas de procrastinación crónica. Revista de Psicología, 23, 114-138.

Arias, F, Varela D, Loli A \& Quintana M. (2003). El compromiso organizacional y su relación con algunos factores demográficos y psicológicos. Revista de Investigación en Psicología, 6(2), 13-25. Arias, W. \& Jiménez, N. (2012). Estudio comparativo del síndrome de burnout en enfermeras, policías y docentes de Arequipa. Revista de Psicología de Arequipa, 2, 180-206.

Blitchtein-Winicki, D. \& Reyes-Solari, E. (2012). Factores asociados a violencia física reciente de pareja hacia la mujer en el Perú, 2004-2007. Revista Peruana de Medicina Experimental y Salud Pública, 29, 35-43.

Bruce, J. (2007). Nos habiamos choleado tanto: Psicoanálisis y racismo. Lima: Universidad San Martín de Porres.

Bulnes, M. (2003). Recursos y estrategias de afrontamiento al estrés en docentes de centros escolares estatales de Lima Metropolitana. Revista de Investigación en Psicología, 6(1), 13-28.

Bulnes, M., Ponce, C., Huerta, R., Elizalde, R., Santiváñez, W. \& cols. (2004). Percepción del clima social laboral y eficiencia personal 
en en profesionales de la salud del sector público de la ciudad de Lima. Revista de Investigación en Psicología, 7(2), 39-64.

Campos, L. (2009). Los estilos de vida y los valores interpersonales según la personalidad en jóvenes del departamento de Huánuco. Revista de Investigación en Psicología, 12, 89-100.

Caravedo, B., Rotondo, H. \& Mariátegui, J. (1963). Estudios de psiquiatría social en el Perú. Lima: Ediciones del Sol.

Cárdenas, N., Crisóstomo, M., Neira, E., Portal, D., Ruiz, S. \& Velásquez, T. (2005). Noticias, remesas y recados de Manta. Lima: Demus. Carpio, R. \& Alay, D. (2012). Modelo ecológico aplicado a la conducta antisocial. Revista de Psicología de Arequipa, 2(2),167-179.

Caycho, T. (2010). Estilos de pensamiento en alumnos de quinto año de secundaria de diferentes niveles socioeconómicos de la ciudad de Lima. Revista de Investigación en Psicología, 13, 41-52.

Cedro. (2010). El problema de las drogas en el Perú. Lima: Autor.

Copestake, J. (2009). Wellbeing and development in Peru: Global and local views confronted. 2009 Congress of the Latin American Studies Association. Río de Janeiro, Brasil, junio 11-14.

De Soto, H. (2000). The mystery of capital: Why capitalism thriumphs in the Weste and fails everywhere else. Nueva York: Basic Books.

De Soto, H., Ghersi, E. \& Ghibellini, M. (1986). El otro sendero. Lima: Editorial El Barranco.

Delgado, A. (2003). El síndrome del "burnout" en profesores de educación secundaria de Lima Metropolitana. Revista de Investigación en Psicología, 6, 49-72.

Escurra, M. (2003). Sistema de valores en estudiantes de quinto de secundaria dee Lima Metropolitana pertenecientes a diferenters estratos socioeconómicos. Revista de Investigación en Psicología, $6(1)$.

Escurra, M. \& Delgado, A. (2008). Relación entre disposición al pensamiento crítico y estilo de pensamiento en alumnos universitarios de Lima Metropolitana. Persona, 11, 143-175. 
Espinosa, A. (2008). Decidiéndose por el mal menor. El rol de las emociones en las elecciones peruanas del 2006. Revista Psicología Politica de la Universidad de Valencia, 37, 47-70.

Espinosa, A. (2010). Estudios sobre identidad nacional en el Perú y sus correlatos psicológicos, sociales y culturales. Tesis doctoral. San Sebastián, España: Universidad del País Vasco.

Espinosa, A. \& Calderón-Prada, A. (2009). Relaciones entre la identifad nacional y la valoración de la cultura culinaria peruana en una muestra de jóvenes de clase media de Lima. Liberabit, 15. http://www.pepsic.bvsalud.org

Espinosa, A., Calderón-Prada, A., Burga, G. \& Güímac, J. (2007). Estereotipos, prejuicios y exclusión social en un país multiétnico: el caso peruano. Revista de Psicología, 25(2), 295-338.

Espíritu, N. (2009). Comportamiento ecológico y creencias ambientales en estudiantes de la Facultad de Psicología de la Universidad Ricardo Palma. Teoría e Investigación en Psicología, 18, 71-92.

Ferrándiz, J., Ibáńez, C. \& Espinosa, A. (2011). Racismo 2.0: expresiones de prejuicio en las redes sociales virtuales tras las elecciones generales de 2011. Revista Politai, 3, 75-83.

Flórez, J. \& Salas, E. (2011). Industrial and organizational psychology in Latin America: The Peruvian story. The IndustrialOrganizational Psychologist, 48. Recuperado de http://www.siop. org/tip/april11/toc.aspx.

Franco, C. (1980). Imagen de la sociedad, valoración de la participación política y personalidad. Revista Latinoamericana de Psicología, 12, 277-292.

Frisancho, S. (2010). Emociones morales y corrupción judicial: un estudio exploratorio. Revista Postconvencionales, 1, 66-82.

Frisancho, S. \& Reátegui, F. (2009). Moral education and post-war societies: The Peruvian case. Journal of Moral Education, 38, 421-443.

Genna, K., Espinosa, A. \& Páez, D. (2010). Cómo los vemos, cómo nos vemos. Influencia de la comparación social entre Perú y Chile en la identidad nacional peruana. Psicología Política, 41, 81-108. 
Herrera, D. (Ed.) (2009). Teorías contemporáneas de la motivación: una perspectiva aplicada. Lima: Pontificia Universidad Católica del Perú.

Herrera, D. \& Lens, W. (2009). Importancia de la perspectiva del tiempo futuro en el proceso de inserción social. En D. Herrera (Ed.), Teorias contemporáneas de la motivación: una perspectiva aplicada. Lima: Pontificia Universidad Católica del Perú.

House, R. J., Hanges, P. J., Javidan, M., Dorfman, P. W. \& Gupta, V. (2004). Culture, leadership, and Organizations: The GLOBE study of 62 societies. Thousand Oaks, CA: Sage Publications.

Kramer, R. M. (1999). Trust and distrust in organizations: Emerging perspectives, enduring questions. Annual Review of Psychology, 50, 569- 598.

Kudó, I., Velásquez, T., Iza, M., Ángeles, A., Pezo, C. \& cols. (2005). Una experiencia de intervención en crisis en el sur del Perú: brigadas psicológicas. Revista de Psicología, 23 (2), 295-336

Lara, A. (2005). Salud comunitaria. Lima: CEDRO.

Le, H., Oh, I-S., Robbins, S. B., Illies, R., Holland, E. \& cols. (2011). Too much of a good thing: Curvilinear relationships between personality traits and job performance. Journal of Applied Psychology, 96, 113-133.

León, F. R. (1978). Control del "error de reciprocidad" en la evaluación del desempeño docente. Revista Latinoamericana de Psicología, $10,351-361$.

León, F. R. (1984). El eje fecundatorio norte-sur del Perú: una interpretación psicológica. Revista de Psicología, 2 (1-2), 95-111.

León, F. R. (1987). Las drogas y las madres sureñas y norteñas: el eje psicoactivo norte-sur del Perú. Socialismo y Participación, 37, 123-129.

León, F. R. (1996). La orientación valorativa del adolescente peruano: hallazgos e implicancias. En F. Morante y L. Soberón (Eds.), Género, sexualidad y población desde la perspectiva de las ciencias sociales (pp. 11-44). Lima: Fomciencias. 
León, F. R. (1999). Peru: Providers' compliance with quality of care norms. Lima: Population Council.

León, F. R. (2011). Latitud sur y control económico del hogar por la mujer peruana. Revista de Psicología, 29, 361-388.

León, F. R. (2012a). Predicting contraceptive use from an egalitarian model of women's overall household power vis-à-vis conventional power models and third variables. Journal of Biosocial Science, publicado en línea el 9 de noviembre.

León, F. R. (2012b). Una teoría psicobiogeográfica del poder doméstico de la mujer. Revista Peruana de Psicología y Trabajo Social,, 1, 29-43.

León, F. R. (2012c). The latitudinal tilts of wealth and education in Peru: Testing them, explaining them, and reflecting on them. Economía, 35, 60-102.

León, F. R. (2012d). Ajuste de la violencia familiar peruana a la teoría psicobiogeográfica de la salud mental. Revista de Psicología, 30 (2), 341-369.

León, F. R., Arévalo, M., Lundgren, R., Jennings, V., Huapaya, A. \& cols. (2007a). Four criteria to evaluate providers' service-delivery response to new contraceptive introduction. Evaluation Review, 31, 364-390.

León, F. R., Brambila, C., De la Cruz, M., García Colindres, J., Morales, C. \& Vásquez, B. (2005). Providers' compliance with the Balanced Counseling Strategy in Guatemala. Studies in Family Planning, 36, 117-126.

León, F. R., Lundgren, R., Huapaya, A., Sinai, I. \& Jennings, V. (2007b). Challenging the courtesy bias interpretation of clients' favorable perceptions of family planning delivery. Evaluation Review, 31, 24-42.

León, F. R., Lundgren, R., Sinai, I., Jennings, V. (2011). The role of need for contraception in the evaluation of interventions to improve access to family planning methods. Evaluation Review, 35, 3-13. 
León, F. R., Monge, R., Zumarán, A., García, I. \& Ríos, A. (2001). Length of counseling sessions and the amount of relevant information exchanged: A study in Peruvian clinics. International Family Planning Perspectives, 27, 28-33.

León, F. R., Ríos, A. \& Zumarán, A. (2005). Training x trainee interactions in a family planning intervention. Evaluation Review, 29, 576-590.

León, F. R., Ríos, A., Zumarán, A. \& Bratt, J. (2003). Perú: La Estrategia de Consejería Balanceada. México: Population Council.

León, F. R., Vernon, R., Martin, A. \& Bruce, L. (2008). The Balanced Counseling Strategy: A toolkit for family planning service providers. Nueva York: Population Council.

León, R. (2010). Cualidades y defectos de los peruanos: Su relación con la herencia colonial. Revista de Investigación en Psicología, 13, $175-190$.

Livia, J. (2008). La producción científica y los estudios de post grado en el Perú. Interamerican Journal of Psychology, 42, 431-445.

Loli, A. E., Aliaga, J., Del Carpio, J., Vergara, A. \& Aliaga, R. (2011) Actitudes de creatividad y emprendimiento y la intención de desarrollar un negocio en estudiantes de la Universidad Nacional Agraria - La Molina. Revista de Investigación en Psicología, 14, 209-234.

Loli, A., Arias, F., Alarcón, J. \& Loli, R. (2008). Agotamiento laboral en profesionales de salud de Lima Metropolitana. Revista de Investigación en Psicología, 11, 93-119.

Loli, A. \& Cuba, E. (2007). Autoestima y compromiso organizacional en trabajadores de una universidad pública de provincias. Revista de Investigación en Psicología, 10, 103-108.

Loli, A. E., Dextre, E., Del Carpio, J. \& De la Jara, E. (2010). Actitudes de creatividad y emprendimiento en estudiantes de la universidad nacional de ingeniería y su relación con algunas variables sociodemográficas. Revista de Investigación en Psicología, 13, 139-151. 
Malvaceda, E. (2010). Nakari - Formas culturales de sufrimiento tras la violencia política en el Perú. Revista de Investigación en Psicologia, 13, 129-138.

Malvaceda, E., Espinoza, J., Rivera, I., Vega, A., Oria, R. \& cols. (2012). Análisis psicosocial del sensacionalismo político en la prensa escrita: elecciones municipales 2010, Lima, Perú. Revista Peruana de Psicología y Trabajo Social, 1, 129-140.

Martinez, P. (2009). Perspectiva temporal futura en la adolescencia tardía: transición a la adultez. En D. Herrera (Ed.), Teorías contemporáneas de la motivación: una perspectiva aplicada (pp. 321-336). Lima: Pontificia Universidad Católica del Perú.

Matos, L. \& Lens, W. (2009). Estudios en el campo educacional sobre la cultura escolar y las metas de logro en profesores y estudiantes: un estudio en escuelas secundarias peruanas. En D. Herrera (Ed.), Teorias contemporáneas de la motivación: una perspectiva aplicada (pp. 39-62). Lima: Pontificia Universidad Católica del Perú.

Miljanovich, M., Martina, M., Huerta, R. E., Torres, S., Camones, F. (2010). Perú: Mapa de violencia familiar, a nivel departamental, según la Endes 2007-2008. Características e implicancias. Revista de Investigación en Psicología, 13 (2), 191-205.

Montero, M. (1984). La psicología comunitaria: orígenes, principios y fundamentos teróricos. Revista Latinoamericana de Psicología, 16, 387-400.

Montero, V. (2008). Análisis psicosocial del discurso de la prensa sensacionalista peruana y las actitudes de sus lectores. Revista de Investigación en Psicología, 11, 153-181.

Ocrospoma, R. (2003). Valoración de los docentes por dos grupos de estudiantes de psicología de la Universidad Ricardo Palma. Teoría e Investigación en Psicología, 11, 117-130.

Orellana, O. (2005). Psicología y mestizaje: una aproximación histórica y psicoeducativa. Revista de Investigación en Psicología, 8, 13-28. Orellana, O., García, L., Alvites, J., Salazar, M., Sotelo, L. \& cols. (2008). Representaciones sociales sobre el psicólogo en profesores de la educación básica pública y privada de Lima (costa) y 
provincias (sierra y selva). Revista de Investigación en Psicología, 11, 41-54.

Orellana, O., García, L., Sarria, C., Morocho, Herrera, E. \& cols. (2007). Perfil profesional de competencias del psicólogo sanmarquino. Revista de Investigación en Psicología, 10, 111-136.

Palacios, J., García, A. \& Flores, E. (2010). Perfiles emocionales en madres cuidadoras del Programa Nacional Wawa-Wasi de Lima Metropolitana. Revista Investigaciones Psicológicas, 1, 3-20.

Pancorbo, G., Espinosa, A. \& Cueto, R. M. (2011). Representaciones esterotípicas y expresión del prejuicio en el Perú: La mirada desde la pobreza. Revista de Psicología, 29, 311-342.

Paredes, M. T. (2011). Las habilidades interpersonales para la negociación según el estilo de vida y el nivel ocupacional en empresas productoras del Perú. Revista de Investigación en Psicología, 14, 109-136.

Paredes, M., De Miguel, J., Carbajal, M. J., Laguna, M. (2004). Construcción social de la comunidad para el desarrollo del Callejón de Huaylas, Caraz. Revista de Investigación en Psicología, 7(1), 81-102.

Paredes, M., Hernández, H., Vicuña, L., Arias, V. \& Rivera, J. (2009). Percepción del conocimiento de las expresiones culturales y su revalorización integral en la comunidad altoandina, Caraz, Ancash, Perú. Revista de Investigación en Psicología, 12, 51-73.

Paredes, M., Hernández, H., Vicuña, L., De Miguel, J., Aliaga, R. \& Laguna, M. (2007). Percepción del conocimiento de la demanda de productos y percepción hacia la interdependencia económica en el caserío Queral, Caraz, Ancash. Revista de Investigación en Psicología, 10, 109-124.

Peltier, B. (2009). The psychology of executive coaching: Theory and application. Nueva York: Routledge.

Pérez, S. (2011). Actitudes hacia la compra de intangibles a través de internet en estudiantes cibernautas de la UNMSM. Revista de Investigación en Psicología, 14, 271-276. 
Pezo, C., Velásquez, T., Valz-Gen, V. \& Pareja, V. (2008). Encuentros de discusión sobre intervención clinica comunitaria. Lima: Pontificia Universidad Católica del Perú.

Ponce C. (2003). Conductas antisociales delictivas y satisfacción familiar en grupos de estudiantes de quinto de secundaria de Lima pertenecientes a diferentes estratos socioeconómicos. Revista de Investigación en Psicología, 6 (1), 104-125.

Ponce, C., Bulnes, M., Aliaga, J., Atalaya, M. C. \& Huertas, R. E., (2005). El síndrome del "quemado" por estrés laboral asistencial en grupos de docentes universitarios. Revista de Investigación en Psicología, 8, 87-112.

Ponce, C., Bulnes, M., Aliaga, J., Delgado, E. \& Solís, R. (2006). Estudio psicológico sobre los patrones de conducta en contextos de tráfico, en grupos de automovilistas particulares y profesionales de Lima Metropolitana. Revista de Investigación en Psicología, 9, 33-64.

Portocarrero, C., Mayorga, E. \& García, M. (2010). Capacidad emprendedora y coeficiente empresarial en estudiantes de administración y psicología de la Universidad Nacional Federico Villarreal. Revista Investigaciones Psicológicas, 1, 62-69.

Prado, T. R. \& Del Águila, M. (2010) Ajuste y satisfacción en parejas que trabajan. Revista Investigaciones Psicológicas, 1, 38-54.

Prahalad, C. K. (2005). The fortune at the bottom of the pyramid: Eradicating poverty through profits. Nueva Delhi: Pearson Education/Wharton School Publishing.

Rappaport, J. (1977). Community psychology: Values, research and action. Nueva York: Holt, Rinehart, and Winston.

Raven, B. H., Schwarzwald, J. \& Koslowski, M. (2006). Conceptualizing and measuring a power/interaction model of interpersonal influence. Journal of Applied Social Psychology, 28, 307-332.

Reátegui, F. \& Frisancho, S. (2012). Education for democracy in Peruvian society. En P. R. Carr, D. Zygier y M. Pruyn (Eds.), Can educators make a difference: Experimenting with, and experiencing democracy in education. Charlotte, NC: Information Age Publishing. 
Rojas, R. (2012) Satisfacción con la vida de operadores mineros. Tesis de Bachiller. Lima: Pontificia Universidad Católica del Perú.

Rottenbacher, J. M. (2012). Vigencia del continuo ideológico izquierda/ derecha durante las elecciones presidenciales de 2011 en Lima, Perú. Revista de Psicología, 30 (2), 281-315.

Rottenbacher, J. M. \& Espinosa, A. (2010). Identidad nacional y memoria histórica colectiva en el Perú. Un estudio exploratorio. Revista de Psicología, 28 (1), 147-174.

Rottenbacher, J. M., Espinosa, A. \& Magallanes, J. M. (2011). Analizando el prejuicio: bases ideológicas del racismo, el sexismo y la homofobia en una muestra de habitantes de la ciudad de Lima-Perú. Revista Psicologia Politica de la Associação Brasileira de Psicologia Politica, 11, 225-246.

Rushton, J. P. (1985). Differential K theory: The sociobiology of individual and group differences. Personality and Individual Differences, 6, 441-452.

Rushton, J. P. (2000). Race, evolution, and behavior. A life-history perspective. Port Huron, MI: Charles Darwin Research Institute.

Schneider, B. (1975). Organizational climates: An essay. Personnel Psychology, 28, 447-479.

Schneider, B., Ehrhart, M. G. \& Macey, W. H. (2012). Organizational climate and culture. Annual Review of Psychology, 64, 361-388.

Sen, A. (2002). Rationality and freedom. Cambridge, MA: Harvard University Press.

Shadish, W. R. \& Cook, T. D. (2009). The renaissance of field experimentation in evaluating interventions. Annual Review of Psychology, 60, 607-629.

Sieler, A. (2010). Coaching to the human soul: Ontological coaching and deep change. En Cox, E., Bachkirova, T. y Clutterbuck, D. (Eds.), The complete handbook of coaching. Londres: Sage.

Solano, D. (2011). La motivación por el servicio público: Entendiendo las claves para tener un buen funcionario público. Lima: Sistema Nacional de Gestión de Recursos Humanos. 
Solf, A. (2006). Motivación intrínseca laboral y su relación con las variables de personalidad orientación a la meta y tesón. Persona, 9, 111-126.

Strauss, A. \& Corbin, J. (1998). Basics of qualitative research. Thousand Oaks, CA: Sage.

Sullivan, J. L. \& Transue, J. E. (1999). The psychological underpinnings of democracy: A selective review of Research on political tolerance, interpersonal trust, and social capital. Annual Review of Pssychology, 50, 625-650.

Tarazona D. (2005). Autoestima, satisfacción con la vida y condiciones de habitabilidad en adolescentes estudiantes de quinto año de media: un estudio factorial según pobreza y sexo. Revista de Investigación en Psicología, 8, 2, 57-65.

Tarazona, D., Jerí de Pinho, S., Bellido, L. (2011). Sistematización de un proceso de formación de promotores comunitarios: reflexiones y lecciones aprendidas sobre la participación y el voluntariado. Revista de Investigación en Psicología, 14, 147-164.

Tarazona, S., Maisch, E. \& Arias, H. (2003). Perfil de empleabilidad del contador público peruano. Revista de Investigación en Psicología, 6, 2, 139-152.

Thorne, C., Centeno, M. \& Wentzell, M. (2009). El clima emocional en la clase: evidencias empíricas en centros educativos. En D. Herrera (Ed.), Teorías contemporáneas de la motivación: Una perspectiva aplicada. Lima: Pontificia Universidad Católica del Perú.

Thorne, C., Velásquez, T. \& Argumedo, D. (2008). Brigadas psicológicas de la PUCP: Una experiencia en el camino hacia la reconstrucción. Lima: Pontificia Universidad Católica del Perú.

Torres. M. \& Lajo, R. (2008). Variables psicológicas implicadas en el desempeño laboral docente. Revista de Investigación en Psicología, 11, 121-138.

Torres, M. \& Lajo, R. (2009). Dominancia cerebral asociada al desempeño laboral de los docentes de una UGEL de Lima. Revista de Investigación en Psicología, 12, 83-96. 
Torres, M. \& Lajo, R. (2011). Relaciones entre ética profesional y desempeño laboral en profesores de un distrito del cono norte de Lima. Revista de Investigación en Psicología, 14, 79-93.

Torres, M., Lajo, R., Campos, E. \& Riveros, M. (2007). Rendimiento académico de los alumnos de una facultad de educación de una universidad pública de lima y su percepción de la calidad académica de los docentes. Revista de Investigación en Psicología, 10, 71-89.

Tueros, M. (2007). Potencial emprendedor juvenil en la región y sus politicas e instrumentos de promoción. Lima: Oficina Internacional del Trabajo.

Tueros, M., Gutiérrez, C. \& Germans, E. (2009). Consideraciones motivacionales en un programa de desarrollo de cultura emprendedora en jóvenes peruanos. En D. Herrera (Ed.), Teorias contemporáneas de la motivación: una perspectiva aplicada. Lima: Pontificia Universidad Católica del Perú.

Velásquez, T. (2007a). Reconociendo y reconstruyendo subjetividades. El encuentro con Manta. En M. Barrig (Ed.), Fronteras interiores: Identidad, diferencia y protagonismo de las mujeres. Lima: Instituto de Estudios Peruanos.

Velásquez, T. (2007b). Salud mental en el Perú: dolor y propuesta. La experiencia de Huancavelica. Lima: CIES, Care.

Velásquez, T., Cueto, R. M., Rivera, M. \& Morote, R. (2011). Construyendo una psicología comunitaria en el Perú. En M. Montero e I. Serrano. (Eds.), Historias de la psicología comunitaria en América Latina: Participación y transformación. Caracas.

Ventura, J. (2003). Condiciones del Marco Nacional Perú. Lima: World Bank Institute.

Ventura, J. (2004a). Estudio de caso: Provincia de Ilo-Moquega, Perú. Lima: World Bank Institute.

Ventura, J. (2004b). Estudio de caso: Villa El Salvador - Lima, Perú. Lima: World Bank Institute.

Ventura, J. (2004c). Estudio de caso: Huaccana - Chincheros, Perú. Lima: World Bank Institute. 
Ventura, J. (2010). La relación entre la empresa y la familia para la reducción de la pobreza Empresas locales en un entorno rural. Estudio de casos. Tesis doctoral. Barcelona: Universitat Ramon Llull.

Vicuña, L., Hernández, H., Paredes, M., Rivera, J. C., Ríos, J., Santillana, C. \& Torres, J. (2006). Percepción, tipos y medidas de control de la corrupción, según el sexo, ciclo académico y la facultad a la que pertenecen los estudiantes universitarios. Revista de Investigación en Psicología, 9, 65-91.

Vicuña, L., Hernández, H., Ríos, J. (2004). La motivación de logros y el autoconcepto en estudiantes de la UNMSM. Revista de Investigación en Psicología, 7 (2), 136-149.

Vicuña, L., Hernández, H., Paredes, M. \& Ríos, J. (2008). Elaboración del test de habilidades para la gestión en la negociación de conflictos. Revista de Investigación en Psicología, 11, 183-200.

Yamamoto. J. \& Feijoo, R. (2007). Componentes émicos del bienestar: Hacia un modelo alternativo de desarrollo. Revista de Psicología, 25 (2), 197-232.

Yamamoto, J., Feijoo, R. \& Lazarte, A. (2008). Subjetive wellbeing: An alternative approach. En J. Copestake (Ed.), Wellbeing and development in Peru: Local and universal views confronted. Nueva York: Palgrave Macmillan.

Yamamoto, J., Meza, R. \& Ríos, Á. (2005). Análisis intercultural de conflictos: valores y concepciones nativas de recursos naturales. IIAP-Focal Bosques.

Yslado, R., Atoche, R., Quispe, M., Ruiz L. \& Medina J. (2011). Factores sociodemograficos intra y extra organizativos relacionados con síndrome de quemarse por el trabajo en profesionales de salud de hospitales. Ancash. Perú. Revista de Investigación en Psicología, 14, 271-276.

Yslado, R., Nuñez, L. \& Norabuena, R. (2010). Diagnóstico y programa de intervención para el síndrome de burnout en profesores de educación primaria de distritos de Huaraz e Independencia (2009). Revista de Investigación en Psicología, 13, 151-162, 
Yukl, G. (2004). Interactions in organizational change: Using influence tactics to initiate change. En J. Boonstra (Ed.), Dynamics of organizational change and learning. Chichester, UK: Wiley.

Zajonc, R. B. \& Bargh, J. (1980). The confluence model: Parameter estimation for six divergent data sets on family factors and intelligence. Intelligence, 4, 349-361.

Zajonc, R. B. \& Markus, G. B. (1975). Birth order and intellectual development. Psychological Review, 82, 74-88.

Zajonc, R. B. \& Mullally, P. R. (1997). Birth order: Reconciling conflicting effects.American Psychologist, 52, 685-699.

Zajonc, R. B. \& Sulloway, F. J. (2007). The confluence model: Birth order as a within-family or between-family dynamic? Personality and Social Psychology Bulletin, 33, 1187-1194.

Recibido: 05 de febrero, 2013 Aceptado: 30 de abril, 2013 